\title{
La otra voz de la Historia de las Bibliotecas \\ Una proyección desde la Argentina y América Latina
}

\section{Alejandro E. Parada}

\begin{abstract}
Secretario de redacción / Información, cultura y sociedad Universidad de Buenos Aires, Facultad de Filosofía y Letras, Instituto de Investigaciones Bibliotecológicas-INIBI, Argentina / aparada@filo.uba.ar / Orcid ID: https://orcid.org/oooo-0oo2-2331-442X
\end{abstract}

\begin{abstract}
Resumen
En este editorial se analizan varios aspectos de la Historia de las Bibliotecas, tanto en el área de la Bibliotecología y la Ciencia de la Información como en las Ciencias Sociales. Se señala la importancia de esta materia en la formación bibliotecaria. Se sugieren una serie de tópicos para abordar su análisis a partir de la Historia Cultural y su encuentro con la Historia Política. Finalmente, se abordan algunos conceptos fundamentales para la Historia de la Bibliotecas, tales como los procesos de "continuidad y discontinuidad", "las migraciones y articulaciones bibliotecarias", "las tipologías de las bibliotecas" en el pasado, "los cambios y las tradiciones", entre otros.
\end{abstract}

\begin{abstract}
The other voice of the History of Libraries. A projection from Argentina and Latin America. This editorial analyses several aspects of the History of Libraries in the area of Librarianship and Information Science, as well as in the Social Sciences. It is noted the importance of this field in the library training. A series of topics are suggested to approach this analysis from the Cultural History perspective and its encounter with the Political History. Finally, some fundamental concepts for the History of Libraries are approached, such as the processes of "continuity and discontinuity", the "migrations and library articulations", the "typologies of libraries" in the past, the "changes and traditions", among others.
\end{abstract}

La Historia de las Bibliotecas no está en vías de extinción en Bibliotecología y Ciencia de la Información (BCI) ni en otros sectores de los estudios sociales. Para muchos constituye una asignatura subalterna, arrinconada en su exiguo nicho por el asedio de las

\section{Palabras clave}

Historia de las Bibliotecas Bibliotecología y Ciencia de la Información Aspectos teóricos

\section{Keywords}

History of Libraries Librarianship and Information Science

Theorical aspects 
nuevas tecnologías y el imperio de las bibliotecas virtuales y sus seductores repositorios; o en otras instancias puede ser observada como un curso académico no obligatorio y, por qué no, una carga incómodamente aceptada como el último bastión humanístico en la educación bibliotecaria y una unidad menor (tal vez "una ciencia auxiliar") de la Historia. Pero en líneas generales, esto suele ocultar una verdad que, a corto o mediano plazo, termina por imponerse. La verdad es que la Historia de las Bibliotecas (dejemos a un lado la Historia del Libro) resulta fundamental para la educación bibliotecaria y para numerosas especialidades de la Modernidad tardía o posmodernismo.

En los últimos veinte años han aparecido varias obras sobre este tópico. Solo por citar algunos ejemplos en la esfera internacional y latinoamericana, mencionaremos las siguientes: Historia de las bibliotecas: de Alejandria a las bibliotecas virtuales de Frédéric Barbier (2015a); Library:An Unquiet History de Matthew Battles (2003); Part of Our Lives. A People's History of the American Public Library de Wayne A. Wiegand (2015); Libraries and the Enlightenment de Wayne Bivens-Tatum (2012); History of Libraries in the Western World de Michael H. Harris (1999); Historia de las bibliotecas nacionales de Iberoamérica:pasado y presente coordinada por José G. Moreno de Alba y Elsa M. Ramírez Leyva (1995); Bibliotecas coloniales de Alicia Fernández Labeque y Óscar Jorge Villa (2012); Libros en llamas de Lucien X. Polastron (2007); el estudio sociológico Bibliotecas en llamas de Denis Merklen (2016); Libros, lectores y sociabilidades de lectura: una historia de los orígenes de las bibliotecas populares en la Argentina de Javier Planas (2017); y el texto colectivo, de reciente aparición, Bibliotecas y cultura letrada en América latina: siglos XIX y XX, bajo el cuidado de Carlos Aguirre y Ricardo D. Salvatore (2018). Una demostración de que esta pequeña gran disciplina aún sobrevive y, lo más alentador, posee un futuro promisorio en varias áreas de las Ciencias Humanas; sobre todo, en el núcleo de la BCI teniendo en cuenta, por añadidura que, conjuntamente con la Bibliografía, es uno de los campos que fundó el hacer y el acontecer bibliotecario.

En otro editorial se han esbozado algunos aspectos de la "Bibliotecología e Historia del Libro y de las Bibliotecas" (Parada, 2012), pero los vertiginosos cambios que se han producido en las recientes investigaciones, requiere de nuevos acercamientos que, indefectiblemente, están reestructurando la totalidad de sus módulos y unidades.

En cierta medida, esta pujante reaparición de las bibliotecas como objeto de estudio resulta, si bien no una novedad, un llamado de atención sobre nuestra formación profesional para comprender las "dimensiones del pasado" entramadas con el presente y el futuro. En este contexto, ¿por qué la historia de las bibliotecas cumple un papel de importancia en el universo bibliotecario y en otras ciencias? En primer término, porque su análisis tiene una alta complejidad que escapa a las experticas técnicas lineales. Por el contrario, despliega su historiografía a partir de diversas perspectivas actuales. Perspectivas que dejan a un lado la clásica erudición académica de su historia. Ya que las recientes textualidades sobre cómo poner en texto a las bibliotecas en el tiempo, específicamente, introducen tendencias históricas modernas para meditar desde "otras miradas y con otra voz" el papel de esas instituciones, tales como la Historia Política, la Historia Institucional, la Historia Social, la Nueva Historia de la Cultura, la Historia de la Economía, la Historia Oral, la Historia del Arte, las aproximaciones antropológicas, sociológicas, literarias, y muchas más.

Cada disciplina tiene su propia retórica del lenguaje pero, además, en ella hay elementos que operan como disparadores de nuevos pensamientos. Es por ello que en el presente no se puede hacer Historia de las Bibliotecas sin Historia Política. No todo en materia de libros, lecturas y bibliotecas son únicamente "estudios culturales" a secas, como si esta tendencia sea una especie de demiurgo inevitable. Las bibliotecas, como "capitales simbólicos en potencia," están atravesadas por los procesos de empoderamiento; enclavadas en escenarios de disputas y combates por las ideas y el conocimiento. Esa 
extensión territorial de los libros (la Biblioteca), el lugar durante por más de quinientos años habitaron los impresos, constituye una espacialidad determinada por el universo material (por lo menos hasta fines de la centuria pasada, antes del advenimiento de la inmaterialidad digital); un sitio donde las bibliotecas invocan también sus corporeidades y sus itinerarios determinados por el consumo, el capital y las vicisitudes del mercado que regula sus contenidos (o carencia de contenidos). La Historia de las Bibliotecas, indudablemente, siempre nos recuerda que los "capitales simbólicos" que albergan, al mejor estilo de Bourdieu, condicionan nuestra manera de concebirlas desde el punto de vista histórico y bibliotecológico.

Hoy en día gestionar una biblioteca en zonas carenciadas, o luchar por el desarrollo de la colección ante la ausencia de presupuesto, o confrontar la desidia del Estado que abandona sus responsabilidades culturales, o trabajar por la inclusión de segmentos desclasados, y otros emprendimientos similares, constituyen en realidad un conjunto de prácticas cuyos antecedentes se encuentran en la larga, constante y activa "Historia de la Historia de las Bibliotecas". Un proceso que solo puede abordarse desde la Historia Política de cada estado. Es por ello que cuando estudiamos esta materia en BCI tenemos la oportunidad, tal vez un privilegio único, de ser conscientes de que estamos desplegando y defendiendo los derechos civiles y ciudadanos de los usuarios que confían en nuestras habilidades tanto profesionales como humanas.

Un segundo tema de capital importancia que, sin duda, emerge en la dinámica histórica de dichas agencias en la época moderna, es la debilidad de las bibliotecas en América Latina en tanto proyectos de larga duración cuando se las compara con las europeas y estadounidenses. Esto posee su correlato, inequívocamente, con el posicionamiento frágil de nuestra profesión dentro de la Ciencias Sociales a lo largo y ancho de Latinoamérica. En esta emergencia, que no es menor, existe una estrecha relación entre la sustentabilidad histórica de nuestras bibliotecas y la consolidación social de la BCI; nos referimos a una concienciación de la "narración histórica" de las bibliotecas latinoamericanas y su identidad en la educación bibliotecaria que las representa en el tiempo.

Otra cuestión profundamente interrelacionada con el tema anterior, se centra en la pregunta siguiente: ¿por qué algunas bibliotecas en América Latina durante el XIX y el XX tuvieron éxito y lograron permanecer y, desgraciadamente, un gran número de ellas fracasaron en su intento? ¿Acaso por su falta de solidez en la sociedad? ¿O por la falta de apoyo de los sectores letrados y dirigentes?

Pero este escenario de discontinuidades en nuestra Historia de la Bibliotecas, presenta también continuidades aleccionadoras. Tomemos, por ejemplo, el caso particular de la Argentina. El primer acto de política cultural que instrumenta la Revolución de Mayo fue fundar una Biblioteca Pública fuera de la égida de la Iglesia y gestionada por el nuevo gobierno revolucionario. Esta biblioteca, destinada a personas que dejaban de ser vecinos para ir transformándose, lentamente, en ciudadanos, en 1884 se transformó en la Biblioteca Nacional de la República Argentina. Atravesó, con innumerables vicisitudes, el conflictivo y fratricida siglo XIX rioplatense, y hoy es la Biblioteca Nacional Mariano Moreno. He aquí un ejemplo de continuidad en medio de la "discontinuidad bibliotecaria". Veamos otro ejemplo. En 1870, por la Ley No. 419, Domingo F. Sarmiento crea las bibliotecas populares que, con sus idas y venidas, llegan hasta la actualidad con centenares de estos establecimientos en el país. Acaso una de las construcciones federales más generosas y educadoras que nos invocan desde el fondo de nuestra historia. Nos hallamos, asimismo, ante otra continuidad.

En consecuencia, uno de los temas latentes que se nos manifiesta en la Historia de las Bibliotecas es la necesidad de estudiar el concepto de continuidady discontinuidad e incorporarlo al contenido de nuestros planes de estudio, ya que en América Latina, en 
materia de libros y bibliotecas, el escenario siempre suele presentarse bajo el signo de lo "continuo y lo discontinuo".

Un tercer acercamiento al relato histórico de las bibliotecas de nuestras naciones, casi de características ineludibles, se diseña en el concepto que identifica los cambios y las tradiciones. Varias bibliotecas nacionales de Latinoamérica son consecuencia de los procesos revolucionarios de emancipación del imperio español. Pero la mayoría de las europeas tienen su inicio en los fondos bibliográficos de la realeza y la nobleza. Esto sugiere otra pregunta: ¿es posible y en qué medida podemos vincular ambos casos? Y, por ende, ¿cuáles serían los planteos discursivos para desarrollar una Historia Comparada de las Bibliotecas del punto de vista transatlántico? (Larraz Elorriaga, 2010).

Pero esto último involucra un asunto aún de mayor importancia y que necesariamente implica un estado de alerta: la inclinación de los historiadores de las bibliotecas de América Latina a elaborar sus discursos desde un posicionamiento en el eurocentrismo y la mirada anglosajona. Esta situación, en muchos casos, deja de lado las realidades de nuestros países $\mathrm{y}$, lo que es más distintivo, el origen revolucionario de muchas de las bibliotecas nacionales de la región en siglo XIX. Además, si se profundiza en esta vertiente, ¿de qué modo, mediante qué prácticas y con qué concepciones filosóficas e ideológicas se administraron estas instituciones hasta el día de hoy? Incluso, por qué los intelectuales que dirigieron estos grandes acervos nacionales, tal el caso de Ricardo Palma en el Perú y Paul Groussac en la Argentina, alentaron el trasplante de los usos europeos a realidades de una complejidad tan diversa y diferente. Ciertamente, en las escuelas de BCI se debería abordar esta heterogénea y ambivalente geografía que plantean "los cambios y las tradiciones" en la propia génesis de la Historia de las Bibliotecas en Latinoamérica.

Todavía es posible incursionar en diversas sutilidades acerca de la temática expuesta. Es necesario -me refiero a una deuda en la historiografía de esas agencias- establecer una "nueva tipología de las bibliotecas en América Latina" desde el período colonial hasta mediados del siglo pasado. Por supuesto, observaríamos la presencia de varios tipos clásicos y tradicionales: bibliotecas de órdenes religiosas, particulares, públicas, circulantes, de institutos de enseñanza, universitarias, populares, especializadas, especiales, escolares, etc.

No obstante, si tuviéramos una amplia y plural tipificación de las bibliotecas, también sería posible identificar algunas migraciones y articulaciones bibliotecarias poco estudiadas. Se detectaría, por ejemplo, que las bibliotecas de las congregaciones religiosas (esto sucedía en Buenos Aires y en otras ciudades coloniales) a partir de mediados del Siglo XVIII, prestaban sus libros a personas influyentes, tanto peninsulares como españoles americanos, y que de hecho, como lo afirma Rípodas Ardanaz, operaban como "cuasi públicas" (1999, 3: 249). Y citando otra muestra tomada al azar, el caso puntual de que muchas bibliotecas particulares (un ejemplo notable es la del funcionario porteño Facundo de Prieto y Pulido en el último tercio del Setecientos) establecieron redes de lectores al prestar sus obras a una gran cantidad de usuarios vinculados o no a su círculo íntimo (Parada, 2002), entre otras muchos entrecruzamientos que ampliarían los tradicionales "tipos de bibliotecas" del período estudiado y, por lo tanto, enriquecería la concepción del universo lector del pasado en nuestros países.

Estas últimas orientaciones de la Historia de las Bibliotecas, donde se cruzan las movilizaciones políticas, la modificación de las tipologías y las migraciones los de elencos bibliotecarios, se visibilizan en forma muy clara en los últimos capítulos del libro coordinado por Aguirre y Salvatore (2018); especialmente en la contribución del historiador Alfredo Alzugarat (2018), quien aborda los nuevos significados de las bibliotecas que gestaron los presos políticos en Uruguay y que hasta la fecha no habían sido tenidos en cuenta. Esta rica pluralidad temática de la Historia de las Bibliotecas en nuestro continente es sobre la cual vale la pena escribir e investigar. 
Me interesaría realizar un último comentario en este editorial. ¿Cómo los procedimientos de catalogación (de influencia europea, vaticana, o estadounidense) y los procesos de clasificación que imperaron en el universo latinoamericano del pasado (Dewey, Brunet, CDU, De Bure o la adoptada por la Library of Congress) influyeron en el mapa del conocimiento de nuestras bibliotecas nacionales? Porque en dicho punto, en el área de la clasificación del orden de los libros (Chartier, 1996; Burke, 2002), se visualiza cómo los organizadores de estas instituciones se apropiaron y pensaron el "capital simbólico" que tenían en sus manos. Particularmente, estamos ante otro reto para el futuro en la Historia de las Bibliotecas en América Latina.

Muchos de estos aspectos que comentamos han sido rescatados por Frédéric Barbier en la insoslayable introducción a su libro titulada "La biblioteca: las palabras y las cosas" (2015b), donde subraya, entre otros elementos, el pasaje de la biblioteca tradicional y erudita a la complejidad de accesos actuales, la importancia de la historia material del pensamiento y "el imperativo de la historia instrumental" dado por los intelectuales y las técnicas bibliotecarias en su ordenamiento del mundo de las bibliotecas, la significación de estas instituciones en su rol de transferencia y legado cultural en las distintas épocas, la significación de las modalidades de usos, prácticas y apropiaciones de dichas transferencias, etc. (Barbier, 2015b). También es oportuno agregar la incidencia de los cambios de las representaciones culturales que afectaron a la lectura y, por lo tanto, a los contenidos textuales de las bibliotecas, y que estas mutaciones de "lo leído" no solo conformaron los contenidos de estas instituciones sino que, además, crearon nuevasformas de leerdentro de las bibliotecas.

Además, aunque parezca audaz, es el momento de pensar que resultaría de interés estructurar ciertas líneas de investigación de una Historia de las Bibliotecas no anclada, en forma exclusiva, con la Historia del Libro. Esta afirmación puede sonar como fuera de lugar, pero muchas veces se asocia el universo del libro con una contundencia que opaca la génesis histórica de las bibliotecas; no obstante, estas últimas tienen su propia dinámica como institución social, antropológica y política que, en muchas oportunidades, tienen objetivos paralelos o bien diferentes a la materialidad que impone la civilización impresa. Esto implica narrar las bibliotecas dentro y, a la vez, fuera de la contundente hegemonía del libro. Martyn Lyons y Rita Marquilhas (2018:16) ya han señalado que la Historia de la Cultura Escrita debe ampliarse a toda marca con significación realizada en cualquier soporte, por lo tanto, esta posición influye en la ampliación de accesos a la Historia de las Bibliotecas.

Todo esto y mucho más nos sugieren los interrogantes esbozados en este breve texto. Sin embargo, todavía resta imbricar la Historia de las Bibliotecas a una macrodisciplina que le brinde sentido y le otorgue una gran variedad de herramientas para analizar su propia historia. En dicho marco, entonces, resulta fundamental abordar una Historia de las Bibliotecas en el centro de la Historia de la Cultura Escrita y no solo configurarla desde el punto de vista librario e impreso. Nos referimos a rediseñar permanentemente a las bibliotecas como dispositivos culturales similares a seres vivos, donde su comprensión demanda un estudio panorámico ligado con la Historia de la Edición, la Historia de la Oralidad, la Historia de la Escritura y la Historia de la Lectura y, por supuesto, pensada desde las entrañas de la propia BCI. Una forma de articular nuestra formación profesional con los conceptos ontológicos y epistemológicos de "pensar una biblioteca" en el territorio de la temporalidad y la duración (oral, manuscrita, impresa, digital). En definitiva, llevar a cabo el esfuerzo de comprender por qué nuestras bibliotecas devinieron en aquello que son en la actualidad. 


\section{Q Referencias bibliográficas}

》Aguirre, Carlos y Ricardo D. Salvatore, eds. 2018. Bibliotecas y cultura letrada en América Latina: siglos XIX y XX. Lima: Pontificia Universidad Católica, Fondo Editorial.

"Alzugarat, Alfredo. 2018. Cultura y resistencia: las bibliotecas de presos políticos en Uruguay (1968-1985). En Bibliotecas y cultura letrada en América Latina: siglos XIX y XX. Lima: Pontificia Universidad Católica, Fondo Editorial. p. 335-359.

» Barbier, Frédéric. 2015a. Historia de las bibliotecas: de Alejandría a las bibliotecas virtuales. Buenos Aires: Ampersand.

»Barbier, Frédéric. 2015b. La Biblioteca: las palabras y las cosas. En su Historia de las bibliotecas: de Alejandría a las bibliotecas virtuales. Buenos Aires: Ampersand. p. 15-37.

» Battles, Matthew. 2003. Library. An Unquiet History. Nueva York; London: W.W. Norton \& Co.

"Bivens-Tatum, Wayne. 2012. Libraries and the Enlightenment. Los Angeles: Library Juice Press.

»Burke, Peter. 2002. Historia social del conocimiento. De Gutenberg a Diderot. Barcelona, Buenos Aires: Paidós.

"Chartier, Roger. 1996. El orden de los libros. Lectores, autores, bibliotecas en Europa entre los siglos XIV y XVIII. Barcelona: Gedisa.

"Fernández Labeque, Alicia y Óscar Jorge Vila. 2012. Bibliotecas coloniales: libros, lecturas y bibliotecas en América Española y la Banda Oriental durante el período colonial. Montevideo: Ediciones de la Banda Oriental; Biblioteca Nacional.

» Harris, Michael H. 1999. History of Libraries in the Western World. 4th ed. Lanham, Maryland; London: Scarecrow.

»Larraz Elorriaga, Fernando. 2010. Una historia transatlántica del libro: relaciones entre España y América Latina (1936-1950). Gijón: Trea.

»Lyons, Martyn y Rita Marquilhas, comps. 2018. Un mundo de escrituras. Aportes a la historia de la cultura escrita. Buenos Aires: Ampersand.

"Merklen, Denis. 2016. Bibliotecas en llamas: cuando las clases populares cuestionan la sociología y la política. Los Polvorines: Universidad Nacional de General Sarmiento.

»Moreno de Alba, José G. y Elsa M. Ramírez Leyva, coords. 1995. Historia de las bibliotecas nacionales de Iberoamérica: pasado y presente. México: Universidad Nacional Autónoma de México.

"Parada, Alejandro E. 2002. Una biblioteca circulante particular en el Buenos Aires del Setecientos: el "Cuaderno de préstamos" de Facundo de Prieto y Pulido (1779-1783). En su De la biblioteca particular a la biblioteca pública. Buenos Aires: Instituto de Investigaciones Bibliotecológicas (INIBI), FFyL (UBA). p. 29-102.

»Parada, Alejandro E. 2012. Bibliotecología e Historia del libro y de las Bibliotecas. En Información, cultura y sociedad. No. 26, 7-11.

"Planas, Javier. 2017. Libros, lectores y sociabilidades de lectura: una historia de los orígenes de las bibliotecas populares en la Argentina. Buenos Aires: Ampersand. 
»Polastron, Lucien X. 2007. Libros en llamas. Historia de la interminable destrucción de bibliotecas. México: Fondo de Cultura Económica.

"Rípodas Ardanaz, Daisy. 1999. Libros, bibliotecas y lecturas. En Academia Nacional de la Historia. Nueva Historia de la Nación Argentina: 3. Período español (1600-1810). Buenos Aires: Planeta. p. 247-279.

»Wiegand, Wayne A. 2015. Part of Our Lives. A People's History of the American Public Library. Nueva York: Oxford University Press. 
